\title{
0 alpinismo: Uma experiência no (pelo) corpo
}

\author{
Ana L. Pereira \\ https://doi.org/10.5628/rpcd.05.03.311
}

\author{
Universidade do Porto \\ Faculdade de Desporto \\ Portugal
}

\section{RESUMO}

A sociedade ocidental caracteriza-se pelo monopólio da visão sobre os demais sentidos, provocando um incremento na valorização da imagem corporal. Mas, para além de ser uma sociedade mediática, valoriza-se a auto-realização e auto -expressão, objectivos possíveis de concretizar no tempo livre e lazer. É sobre o alpinismo, uma actividade física de lazer e que encerra riscos que colocam a integridade física em causa, que este estudo incide. Perante a possibilidade de ocorrerem acidentes que adulteram o corpo do alpinista e o afastam da imagem preconizada pela sociedade, é de questionar a valorização que este confere ao corpo. Assim, os objectivos deste trabalho foram compreender os sentidos expressos e atribuídos ao alpinismo e compreender as representações do corpo em alpinistas. Para isso foram efectuadas entrevistas semi-estruturadas a vinte alpinistas, tendo essas entrevistas sido submetidas à análise de conteúdo. Através do processo hermenêutico para as categorias criadas, podemos considerar que para os alpinistas deste estudo o corpo é um locus de expressão do valor da estética e o dever um valor essencial para um corpo disciplinado. Esta valorização do dever está subordinada aos valores hedonísticos inerentes à própria actividade, os quais não estão subordinados a nenhum valor que o prazer da conquista. Finalmente, o corpo é percebido pela sua funcionalidade, sendo inclusive menos bem tratado desde que o objectivo se concretize.

Palavras-chave: corpo, alpinismo, valores.

\section{ABSTRACT \\ High-altitude climbing: a body experience}

The western society shows an image monopoly, which evidences as a result an enhancement in the valorization of body appearance. Even though, we live in a society that also valorizes self-expression and selfrealization, aspirations that can be accomplished in leisure time. This paper is about climbing, a leisure and physical activity that entails some risks that may put physical integrity in cause. In this way, since accidents are frequent and may alter climbers' image and lay them far from the 'perfect' body, one can question about the values climber attributes to his body. Thus, our goals were: to understand the feelings expressed by climbing and the representation and valorization of the body among the alpinists. Our data was collected through twenty indepth interviews conducted with climbers. Such interviews were submitted to content analysis. Through a hermeneutic process of the main categories, we can say that for these climbers body is an expression locus for aesthetic. Duty is considered as a fundamental value to obtain a disciplined body. This duty valorization is subordinated to hedonism, which is an inherent value in climbing. Finally, the body is perceived by its functionality and it may even be poorly treated if necessary when one wants to get the top of the mountain.

Key Words: body, climbing, values. 


\section{INTRODUÇÃO}

Temos assistido nas últimas décadas a um verdadeiro boom do corpo, a uma verdadeira explosão na atenção, no cuidado e, por vezes, na obsessão pelo corpo. Este, mais do que nunca, torna-se significante representativo e executivo da identidade, isto é, converte-se na manifestação da pessoa total ${ }^{(38)}$. Na realidade, beleza, saúde, poder, valor simbólico de troca, sedução, objecto de expressão e valorização pessoal, são apenas alguns exemplos que sustentam a importância que é conferida ao corpo na sociedade contemporânea do mundo ocidental. Uma sociedade que apresenta como uma das suas características mais peculiares o monopólio da visão sobre os demais sentidos, uma autêntica ditadura (15). Isto é, uma sociedade da aparência, dominada por um império do visual e transformada, consequentemente, num mundo imaginário, talvez o da hiper -realidade de que nos fala Baudrillard (2). De facto, de acordo com Bragança de Miranda (6), o momento actual é marcado por um aparelhamento estético da existência que se funda na vontade de um 'corpo' ou 'obra' perfeita operada tecnicamente. Este fenómeno provoca e configura um aumento na importância e valorização da imagem corporal, fazendo com que o corpo se transforme numa forma privilegiada de apresentação do eu e, consequentemente, num valor simbólico, isto é, num valor que conduz a um tratamento tal, que parece que da sua aparência depende a nossa situação no mundo ${ }^{(14)}$.

Não obstante, nesta sociedade estetizada, valoriza-se igualmente a criatividade, a auto -realização e a auto expressão, objectivos pessoais que são passíveis de ser concretizados, por exemplo, no tempo livre e lazer. Efectivamente, alguns estudos (para refs ver 39) demonstram que no lazer existe oportunidade para a expressividade e preenchimento pessoal, bem como, para o desenvolvimento da auto-identidade. Neste sentido, assistiu-se ao longo da modernidade, principalmente nas sociedades mais diferenciadas, a um aumento do tempo livre decorrente dos processos de industrialização e tecnologização, que é enfatizado pelo cada vez maior número de actividades que se podem classificar como sendo de lazer (9). É neste conte xto que o fenómeno da actividade física enquanto actividade de lazer assume um destaque particular. De facto, é ampla a variedade de activida- des de lazer, em geral, e de desportos e actividades físicas, em particular, que as sociedades comple xas têm para oferecer.

De entre as inúmeras possibilidades de praticar uma actividade física no âmbito do lazer, a opção deste estudo deteve-se na prática do alpinismo de muito elevada e extrema altitude (19). Nesta actividade, os praticantes encontram na natureza um espaço privilegiado para a sua auto -realização e auto-expressão. De facto, o meio artificial onde o homem passa a maior parte do tempo provocou, no último século, um fenómeno social caracterizado por uma procura crescente do contacto com a natureza. Esta procura de práticas desportivas de contacto com a natureza fez emergir um elevado número de clubes dedicados à organização de actividades na natureza, entre as quais o alpinismo. Contudo, esta é uma actividade física que, ao permitir esse contacto com a natureza, encerra em si alguns riscos inerentes à imprevisibilidade do próprio meio natural, à especificidade da actividade e ao próprio sujeito enquanto elemento activo (11) que poderão, eventualmente, colocar a integridade física dos praticantes em causa. Efectivamente, se tomarmos em consideração que nas expedições ao Evereste morre um em cada oito indivíduos (34) e que por cada quatro que atingem com sucesso o cume há um que perde a vida(27), desde logo se torna óbvio que são várias as contingências e os constrangimentos inerentes a esta actividade.

Assim sendo, perante a possibilidade de ocorrerem acidentes que possam resultar na mutilação do corpo do alpinista, afastando -o da imagem corporal preconizada por uma sociedade onde a aparência se assume como um valor simbólico e, até mesmo, como um capital simbólico ${ }^{(5)}$, é de questionar a valorização que o alpinista confere ao seu corpo. Neste contexto, os objectivos deste trabalho foram (i) compreender os sentidos expressos e atribuídos ao alpinismo e (ii) compreender as representações do corpo em praticantes de alpinismo, através dos discursos dos alpinistas.

\section{METODOLOGIA}

Foram efectuadas entrevistas semi-estruturadas (16) a vinte alpinistas com idades compreendidas entre os 25 e os 43 anos. De entre os vinte alpinistas, cinco são de nacionalidade espanhola e apenas um dos 
alpinistas é do sexo feminino. O critério estabelecido para a selecção dos alpinistas baseou-se nas altitudes máximas atingidas por eles durante a sua prática. Assim sendo, foram seleccionados alpinistas com prática da actividade em altitudes superiores a $5000 \mathrm{~m}$ (tabela 1). A opção por este critério prende- se com o facto de, regra geral, a prática do alpinismo de grande altitude estar associada a inúmeros constrangimentos técnicos e climatéricos que tornam a actividade mais comple xa e conferem um maior grau de compromisso do alpinista relativamente à mesma.

Tabela 1: Altitudes máximas atingidas pelos entrevistados.

\begin{tabular}{|c|c|c|}
\hline Alpinista & Altitude máxima & Classif. American Alpine Club Journal \\
\hline 1 & $6000 \mathrm{~m}$ & Extrema Altitude \\
\hline 2 & $5400 \mathrm{~m}$ & Altitude Muito Elevada \\
\hline 3 & $8850 \mathrm{~m}$ & Extrema Altitude \\
\hline 4 & $6088 \mathrm{~m}$ & Extrema Altitude \\
\hline 5 & $5407 \mathrm{~m}$ & Altitude Muito Elevada \\
\hline 6 & $6300 \mathrm{~m}$ & Extrema Altitude \\
\hline 7 & $5200 \mathrm{~m}$ & Altitude Muito Elevada \\
\hline 8 & $8586 \mathrm{~m}$ & Extrema Altitude \\
\hline 9 & $6088 \mathrm{~m}$ & Extrema Altitude \\
\hline 10 & $8000 \mathrm{~m}$ & Extrema Altitude \\
\hline 11 & $8850 \mathrm{~m}$ & Extrema Altitude \\
\hline 12 & $8000 \mathrm{~m}$ & Extrema Altitude \\
\hline 13 & $6000 \mathrm{~m}$ & Altitude Muito Elevada \\
\hline 14 & $5000 \mathrm{~m}$ & Extrema Altitude \\
\hline 15 & $8000 \mathrm{~m}$ & Extrema Altitude \\
\hline 16 & $7160 \mathrm{~m}$ & Extrema Altitude \\
\hline 17 & $7160 \mathrm{~m}$ & Extrema Altitude \\
\hline 18 & $7160 \mathrm{~m}$ & Extrema Altitude \\
\hline 19 & $7160 \mathrm{~m}$ & Extrema Altitude \\
\hline 20 & $7160 \mathrm{~m}$ & \\
\hline & & \\
\hline
\end{tabular}

No que concerne à composição do guião da entrevista, a versão final, submetida a especialistas da área, foi resultado de algumas entrevistas piloto a vários alpinistas. A duração das entrevistas oscila entre os sessenta e os noventa minutos, tendo sido gravadas com autorização prévia.

Os textos obtidos da transcrição das entrevistas a, que assim se constituíram como nosso corpus de estudo, foram submetidos à análise de conteúdo (1) com o intuito de restituir, em certa medida, as 'condições de produção' e o sentido de um texto. Assim sendo, a categorização inerente a esta técnica foi efectuada quer a priori, quer a posteriori(40). Isto é, algumas das questões das entrevistas foram a base para a identificação e a classificação de particularidades inerentes aos alpinistas e à actividade propriamente dita. Não as consideramos como categorias no sentido consignado pela técnica de análise de conteúdo, mas antes como pressupostos que nos permitiram criar as grandes categorias de análise, essas sim, construídas com base no quadro teórico, mas criadas somente após a leitura flutuante do corpus de estudo, ou seja, a posteriori. 
A partir deste pressuposto, e considerando as questões das entrevistas, foram estabelecidos alguns temas para a análise, dos quais emanaram as grandes categorias - o corpo: um locus da experiência; o corpo: na realização de si; o corpo disciplinado; e o corpo 'em risco' - e cuja justificação decorre no próprio processo hermenêutico. Dizemos hermenêutico, na medida em que a sua 'codificação' é proveniente de uma interpretação que pretendíamos não ficasse presa aos processos analíticos referidos. Assim sendo, tentámos descobrir os núcleos de sentido através da hermenêutica, uma vez que esta se preocupa com o sentido ${ }^{(21)}$. Com efeito, as interpretações que emergem do processo hermenêutico podem levar-nos a níveis de compreensão que nos permitem apreender o modo da experiência (20) e a penetrar no cerne do discurso dos entrevistados, tornado texto através da transcrição das entrevistas.

\section{CARACTERIZAÇÃO DO ALPINISMO DE MUITO ELEVADA E EXTREMA ALTITUDE}

Antes de tentar uma análise e interpretação do corpus do trabalho, torna-se necessário efectuar uma breve descrição da actividade em questão para, dessa forma, se conte xtualizar os discursos dos alpinistas. A prática do alpinismo pode ser classificada com base na altitude da montanha a escalar, no tipo de terreno em que se progride (rocha, gelo, neve ou misto) ou na dificuldade técnica atribuída às vias de ascensão. Para o objectivo deste trabalho reteremos uma das classificações respeitante à altitude (ver tabela 2), já que, por um lado, foi este o critério utilizado para a selecção dos entrevistados e, por outro, é desta forma que a maioria dos alpinistas deste estudo categoriza a sua prática de alpinista. Neste conte xto, o alpinismo de muito elevada e de extrema altitude pressupõe que a ascensão se realize em ambientes de alta montanha caracterizados pelos seus terrenos mistos, i.e., ascensões efectuadas em terrenos de rocha e neve e/ou gelo utilizando instrumentos específicos e muito técnicos para a progressão no terreno.
Tabela 2: Classificação da altitude.

\begin{tabular}{|c|c|}
\hline Altitude & Classif. American Alpine Club Journal \\
\hline $1500-2440 \mathrm{~m}$ & Altitude Intermédia \\
\hline $2440-4270 \mathrm{~m}$ & Altitude Elevada \\
\hline $4270-5490 \mathrm{~m}$ & Altitude Muito Elevada \\
\hline $5490-8848 \mathrm{~m}$ & Extrema Altitude \\
\hline
\end{tabular}

As características geográficas e geológicas dos ambientes em que se desenvolve a prática do alpinismo, bem como as suas especificidades, tornam-na numa actividade singular que coloca, muito frequentemente, o praticante em risco. Em primeiro lugar, porque é uma actividade que se realiza num ambiente natural de grande altitude caracterizado por escarpas rochosas ou mistas de elevada pendente e/ou cascatas geladas e com diversos riscos subjacentes. Estes riscos podem incluir queda de pedras ou blocos de gelo, avalanches, ventos fortes e frios, nevões, entre outros, podendo ser ou não previstos, mas impossíveis de eliminar, uma vez que, apesar da precaução do alpinista, são parte integrante deste contexto natural. É ainda de salientar o facto de a estas altitudes, como no caso extremo do Evereste, os alpinistas estarem muito perto dos limites fisiológicos de sobrevivência, mesmo que devidamente aclimatados $\mathrm{b}(10,18)$, devido às extremas condições de rarefacção de oxigénio e às reduzidas temperaturas. Em segundo lugar, a prática do alpinismo desenrolase num ambiente que solicita frequentemente a utilização em simultâneo dos membros superiores e inferiores, tornando -a, por isso, numa actividade fisicamente exigente e tecnicamente complexa. É a combinação destes dois factores que torna o alpinismo distinto de tantas outras actividades (41).

\section{APRESENTAÇÃO E INTERPRETAÇÃO DOS DISCURSOS}

Tendo em conta os objectivos deste trabalho, importa analisar os valores que norteiam a prática do alpinismo, dado serem os valores que enformam a acção humana e que desvelam os seus sentidos (17). Com efeito, são os valores que representam os desejos despertados pelas coisas, sendo na intensidade desse desejo que se desencadeiam as acções humanas (35). Por conseguinte, o valor pode ser entendido como uma figura do desejável, envolvendo, por isso, uma aspiração e uma representação ${ }^{(37)}$. Ora, tendo em 
conta as várias dimensões da pessoa, nomeadamente, a dimensão vital, a prática, a hedonística, a estética, a lógica, a ética e a religiosa, são distintas as ordens de valores que lhes correspondem. Assim sendo, às diferentes dimensões correspondem as respectivas ordens axiológicas que se objectificam na cultura, isto é, no fruto objectivo da acção criadora humana (35).

Fica então evidente que a plena realização do sentido da nossa existência dependerá, igualmente, da concepção que tivermos acerca dos valores (17). Por conseguinte, é de considerar que a prática do alpinismo revele sentidos porque, mais do que aquilo que exteriormente é, expressa valores intrínsecos à pessoa que o pratica, constituindo -se numa metalinguagem que urge interpretar. A partir da sua interpretação é possível apreender o valor que o corpo assume para os alpinistas, logo, a consciência valorada do seu corpo. Assim, na vivência do alpinismo é possível decifrar direcções para o prazer, para a experiência sensorial, para a fruição, para a apreciação estética do ambiente e para a disciplina como algo essencial na obtenção dos objectivos, elementos que contribuem para a criação das categorias a interpretar .

\section{0 corpo: um locus da experiência}

A cada instante descodificamos sensorialmente o mundo, traduzindo -o em informações visuais, auditivas, olfactivas, tácteis ou gustativas, sendo certo que cada comunidade humana elabora o seu próprio universo sensorial com o universo dos sentidos (24). No grupo entrevistado desvenda-se uma representação homogénea do seu universo sensorial, manifestando -se uma ênfase na experiência vivida in loco quando se afirma gostar "das sensações, de sentir frio e sentir o vento na cara...”(\#7)c. O destaque conferido à experiência vivida é reiterado pela maioria dos alpinistas, pois para estes o gozo está em "cada momento, cada passo... gosto da sensação de manipular as cordas e as reuniões, tudo isso me dá gozo!"(\#1). Na montanha, "os próprios movimentos, são como um bailado vertical porque muitas vezes, quando se está a praticar a actividade, há um prazer na forma como se estão a sentir os movimentos, na forma como estamos a fluir..."(\#4). Por isso, “cada gesto que faço é incrível! ... E, sinceramente, tocar na rocha e no gelo estimula-me porque a simples sensação de tocar é importante para mim!”(\#13).
Nos discursos anteriores o corpo pode ser entrevisto como o vector semântico por intermédio do qual se constrói a evidência da relação com o mundo ${ }^{(24)}$, ou, como diria Merleau-P onty ${ }^{(31)}$, como ponto de vista sobre o mundo, isto é, o nosso meio de apreender o mundo. Com efeito, ao analisarmos as narrativas dos alpinistas, compreendemos que a sua actividade é um modo de percepção que convida o corpo e todos os sentidos a estarem em harmonia com o seu ambiente ${ }^{(30)}$, sugerindo que o lugar é, primeiramente, vivido fisicamente. Esta ideia é reiterada por Lewis (25) quando afirma que no mundo da percepção dos sentidos, o mundo real da aventura do alpinismo é mapeado pela navegação táctil do corpo em movimento.

São, sem dúvida, percepções adquiridas e sentidas como significativas na/pela experiência vivida na montanha que parecem conduzir o vector semântico corpo a uma concepção de corpo expressivo. Um corpo expressivo que admite uma valorização do valor estético, dado que, para os alpinistas, a montanha e todo o ambiente em que se desenrola a actividade se torna suporte de valor estético.

Efectivamente, percebe-se nos discursos dos alpinistas uma descrição marcadamente visual, um conteúdo psíquico ou uma ideia que penetra no domínio do sensível e encontra uma expressão plástica, produzindo -se um fenómeno estético (17). Trata-se de uma intuição estética que põe o objecto diante de nós, como uma essência sempre susceptível de percepção sensível e que pode intuir -se no modo como os alpinistas descrevem a montanha, isto é, um local "que tem praticamente todos os ingredientes da arte... A própria magnitude da natureza é uma excelente obra de arte"(\#4). É, como enfatiza outro alpinista, "uma paisagem tão fabulosa! Percebemos a sua verdadeira magnitude quando conseguimos estar no cume da montanha. Muito do prazer que associo ao alpinismo está relacionado com essa sensação"(\#1). Adicionalmente, e "morfologicamente falando, as suas formas, a neve, as rochas, tudo isto me atrai, o silêncio, a tranquilidade..."(\#13).

Nesta valorização estética subentende-se uma valoração dada ao corpo como lugar de experiência do mundo, tornando -se visível a consumação da experiência vivida. Essa experiência pode ser mediatizada no corpo (locus da experiência), pelo corpo (instrumento da experiência) ou, mesmo, apesar do corpo 
(para além do corpo), como é o caso do prazer ou sentimento agradável que se obtém no final de uma escalada. Mesmo que o corpo seja sede de um grande sofrimento ou padecimento, até porque, por vezes, "quando lá estamos, estamos a sofrer..."(\#6). Com efeito, "chegar ao cume... Eu recordo-me que quando estava no cume do Evereste, dizia: Uhau! Quando estás lá em cima apercebes-te que já não há objectivo mais alto para escalar, mas fisicamente estamos um 'trapo'!(\#11).

Porque, de facto, por vezes "custa muito, muito, e ainda estás a subir, e sentes-te muito mal... Mas quando chegas, a recompensa é muito grande!"(\#13).

É um sofrimento consciente, mas passível de ser associado ao prazer que decorre do objectivo concretizado, denotando -se uma ligação muito forte entre o trágico e o hedonismo ${ }^{(29)}$. As palavras de um dos alpinistas parecem ilustrar bem esta conversão do sofrimento em prazer ao assegurar que "tenho muita capacidade de sofrimento!”(\#11). Por isso, impôs-se questionar onde fica o prazer da actividade. "Em $\mathrm{mim}$ mesmo. Penso que as coisas que não requerem esforço não têm sentido! Por outro lado, o mais importante são as coisas que podes conquistar sem que te custe dinheiro, é muito pessoal. O que conseguiste quando subiste à montanha? É ter conseguido subir à montanha!"(\#11). É, pois, de aceitar que para estes alpinistas o hedonismo subjuga o trágico, convertendo -o como meio para a vivência e fruição do próprio hedonismo.

Adicionalmente, demonstram estar cientes que "para fazer uma ascensão a partir dos $7000 \mathrm{~m}$ é preciso dedicar muito tempo à montanha, especificamente, um grande sofrimento"(\#4). Subir uma montanha de elevada altitude, "requer outro esforço no empenho"(\#16). Não obstante, o sofrimento nem sempre é sentido como tal, mas sim, "sofrer entre aspas!"(\#17), provavelmente porque aceitar uma situação como sendo, de facto, penosa retira-lhe o sentido. Efectivamente, parece existir uma fronteira muito ténue entre o sofrimento e o esforço árduo que está inerente à consecução dos objectivos na prática do alpinismo de elevada e extrema altitude e que se expressa nas palavras de outro alpinista: "na realidade, se se sofre é um erro, pois nenhum ser humano gosta de sofrimento! Mas é como numa corrida de fundo, há um momento em que há uma fronteira difícil entre o que é o esforço e a dor. É difícil de dizer: até aqui é esforço e aqui começa a dor..."(\#14). Os esforços sentidos e 'gozados' expressam uma 'audição do corpo', parecendo que o alpinismo é dominado pela procura do prazer, do dinamismo energético e da experiência de si próprio. São esforços vivenciados como busca de uma realização pessoal, através dos quais se manifesta uma centralização em si pela máxima perscrutação corporal. Neste sentido, esta actividade física pode ser englobada nos emblemas mais significativos da cultura individualista centrada no êxtase do corpo, referidos por Lipovetsk $\mathrm{y}^{(26)}$. O corpo torna-se, então, no 'lugar' expressivo e de acção do ser humano e nele tomam forma e concretizam-se as suas potencialidades (38). O corpo converte-se num lugar geométrico de reconquista de si, território a explorar, à espreita para sentir sensações inéditas ${ }^{(22)}$. Por conseguinte, perscrutase a vivência de valores hedonísticos pela experiência através do/no corpo, compreendendo -se uma valorização particular na 'audição' do corpo através dos prazeres cinestésicos e dos quinestésicos. Uma valorização na actividade que confere ao corpo uma configuração de locus da experiência.

\section{0 corpo: na realização de si}

A valorização do esforço parece catalisar a superação de si próprio e a necessidade de ultrapassar obstáculos permitindo, consequentemente, a realização de si. Esta é, aliás, uma reclamação capital da contemporaneidade que, no entender de Lipovetsk $\mathrm{y}^{(26)}$, coloca a descoberta do potencial próprio, ou a vitória sobre si mesmo, como primordiais. Com efeito, é patente nos discursos dos alpinistas uma necessidade de se excederem e conhecerem os seus limites, até porque, como nos lembra Garcia(12), o desporto pode ser compreendido como uma forma de o homem actual se transcender. De facto, quando 'dissecamos' os discursos, subentende-se que este aspecto está presente nos objectivos referidos para a prática do alpinismo (ver tabela 3), designadamente, "fazer a máxima dificuldade para me realizar, para sentir a superação"(\#12), ou "conseguir superar-me tecnicamente e também fisicamente! Trata-se de me vencer a mim próprio!”(\#19) e "querer superar os meus limites"(\#5). Verifica-se, na generalidade dos discursos, uma concordância quanto ao que se espera alcançar na prática do alpinismo, sendo disso mesmo ilustrativo as palavras de um dos entrevistados: "relativamente à actividade em si, tem muito a ver com o atingir desafios e conseguir ultrapassar muitas vezes aquilo que nós pensávamos que até nem conseguiríamos"(\#9). 
Nesta busca de superação contínua de si, através da transposição de obstáculos com dificuldade crescente, subentendem-se algumas das características inerentes ao designado desporto moderno, nomeadamente, o recorde ${ }^{(13)}$. Este parece ser um aspecto relevante para alguns alpinistas, estando bem explícito, quando se refere que "ao chegar ao campo base [do Monte Pumori] que está a $5300 \mathrm{~m}$ já estou a bater um recorde pessoal pois o máximo que estive foi a 4800m"(\#18). Por vezes, o objectivo é escalar as montanhas com mais de $8000 \mathrm{~m}$, "porque são as grandes montanhas. Só há 14! Porque é mais desafiador, porque são as mais altas”(\#8). Para outro dos entrevistados, um dos objectivos inerentes à sua actividade é alcançar os cumes das montanhas mais altas de cada continente, colocando -se, dessa forma, no 'quadro' dos poucos alpinistas a realizar tal feito, tal recorde.

Tabela 3. Objectivos referidos para a prática do alpinismo.

\begin{tabular}{|c|c|c|}
\hline Objectivos & Alpinistas & Total \\
\hline Desfrutar o ambiente da montanha & $1,2,3,4,5,7,9,10,11,12,13,14,15,16,17,19,20$ & 17 \\
\hline Estar fora do ambiente do quotidiano & $1,2,4,7,9,10,11,12,13,20$ & 10 \\
\hline Estar só & $1,2,7,14,15$ & 5 \\
\hline Realizar a actividade alpinismo & $2,3,4,8,9,10,12,13,14,15,18,19,20$ & 14 \\
\hline Superação de dificuldade técnica/logística & $3,4,5,6,7,8,9,10,12,13,14,15,16,17,18,19,20$ & 18 \\
\hline Realização pessoal/conhecimento de outros locais & $3,4,6,8,10,11,12,13,14,15,17,18,19,20$ & 14 \\
\hline Procura do risco & $4,5,12,13,16$ & 5 \\
\hline Reconhecimento & $3,5,6,8,10,11,12,13,14,16,18,20$ & 12 \\
\hline Praticar uma actividade desportiva & $5,8,10,11,13,14,15$ & 8 \\
\hline
\end{tabular}

A importância conferida aos graus de dificuldade já efectuados, bem como às altitudes máximas atingidas, é um aspecto que nos permite inferir que existe, na maioria dos alpinistas, um desejo de ir sempre mais além, de se superar continuamente e de ter elementos concretos que lhe permita essa avaliação pessoal, conforme se verifica no discurso de um dos alpinistas quando afirma que "é conseguir cada vez mais! Se tiver oportunidade para fazer um 8000, eu sigo e entro num 8000!"(\#6).

Face ao exposto, entendemos que o alpinismo detém, em si, características que o colocam a par do 'desporto moderno' pois, sendo uma actividade refle xiva da sociedade, desvela na sua prática elementos particulares da modernidade, designadamente, o progresso contínuo e a superação. Esta ideia de progresso ilimitado é consubstanciada no 'desporto moderno' pela ideia de recorde. O rendimento e o triunfo são a base duma concepção de actividade física em que, através do treino incessante, se busca novos rendimentos, novas vitórias (36) e novas conquistas. Com efeito, pese embora a prática do alpinismo não esteja associada à competição formal, a ideia de recorde torna- se patente pela necessidade de concretizar expedições a montanhas cada vez mais altas, ou com um grau de dificuldade cada vez mais elevado. De facto, o alpinista esforça-se por subir mais alto, por encontrar vias de acesso nunca antes experimentadas - fórmulas de performances originais -, ou seja, ainda que num sentido diferente do da competição subjacente ao desporto moderno, está dominado pela ideia de ser o primeiro e, por isso, introduz uma ideia de profunda competição ${ }^{(4)}$. Por este motivo, é incontestável que "ter uma boa condição física e ter um bom índice de resistência é fundamental para quem pratica alpinismo"(\#2). Assim sendo, o treino afigura-se essencial para a consecução dos objectivos, existindo uma preocupação por parte dos alpinistas em consagrar algum do seu tempo à preparação física e técnica específicas. Como referem alguns alpinistas, "eu corro, escalo em rocha e faço alguma musculação no ginásio e ao fim de semana tento escalar em rocha e em gelo quando é altura dele"(\#2). Porque é "muito importante o treino técnico, andar com os crampons, treinar com o piollet, fazer a escalada em gelo. Correr muito porque isto exige muito em termos cardio-vasculares"(\#19). 
Sob esta perspectiva, parece revelar -se no alpinismo uma orientação através da razão instrumental. Uma orientação que conduz a uma percepção do corpo como um meio, um instrumento de realização de si, pois podemos perceber que para além de ser um locus de experiência per se, é, paralelamente, um meio através do qual se chega a si, se faz pessoa e através do qual se dá sentido à vida. Por conseguinte, colocar o corpo nesta disposição instrumental, algo que tem que ser treinado para alcançar determinado objectivo, manifesta a vivência de valores práticos. Considerando que a prática envolve sempre meios de transformação da realidade, pois não há prática sem meios ${ }^{(35)}$, o corpo - entidade corpórea constitutiva da pessoa - revela-se como um meio que pode ser transformado, neste caso, através do treino, para realização de uma 'melhor' pessoa, para a realização de si. Na realidade, um dos sentidos da prática é 'servir', pois prático é o que serve para outra coisa que é um fim, sendo a coisa prática um meio ${ }^{(35)}$. Ora, prático é um corpo treinado que serve como um meio para alcançar o cume.

\section{0 corpo disciplinado}

Quando o alpinista se refere à disciplina como algo essencial para a consecução dos seus objectivos, pois "mesmo em situações limite há que manter uma passada, não parar ainda que a propensão seja parar para descansar..."(\#8), é possível discernir uma tendência subordinada que perfaz a sua actividade. Uma subordinação dócil de um corpo disciplinado teorizado por Foucault ${ }^{(10)}$. Porém, esta docilidade configura-se como uma opção própria e não como subordinação a qualquer instituição, uma vez que só de forma extremamente disciplinada se poderá alcançar o mais alto dos cumes.

Conforme destacado, a maioria dos alpinistas sente necessidade de uma preparação específica, isto é, de uma forma de disciplinar o seu corpo. Mesmo quando "faz frio e penso: pohh, sair para treinar? A correr à noite! Eu saio! E quando volto a casa, volto diferente, fico melhor do que quando saí de casa porque exercitei o corpo"(\#12). $\mathrm{Ou}$, mesmo que por vezes se possa "estar cansado e não ter disposição", existe "uma espécie de auto-compromisso, tenho que ir, devo ir!”(\#2). Adicionalmente, ser disciplinado parece contribuir decisivamente para a eficácia dos programas de adaptação e aclimatação aos ambientes de elevada e extrema altitude. Com efeito, os alpinistas têm perfeita noção de que "sem aclimatação não sobes a estas montanhas [as dos Himalaias], e o que temos que fazer é irmo-nos adaptando sem pressas a esse meio, fazer um novo organismo, o que é muito difícil. E o nosso organismo rejeita estar aí! Rejeita!”(\#11).

Efectivamente, é necessário ter um corpo e uma vontade preparados e eficientes, quer para realizar as escaladas mais técnicas, com maior grau de dificuldade, quer para conseguir ascender às montanhas de elevada e extrema altitude. Nestas circunstâncias, o corpo disciplinado do alpinista apresenta a relação controlo-disciplina discutida por Foucault, isto é, o controlo impõe a melhor relação entre um gesto e a atitude global do corpo, condição de eficácia e de rapidez ${ }^{(10)}$. Um corpo bem disciplinado forma o contexto de realização do mínimo e do melhor gesto, ou seja, é a base de um gesto eficiente. Por conseguinte, parece subsistir no conte xto do alpinista um biopoder que se materializa em/para si próprio. De acordo com Foucault, o poder disciplinar é um poder que, em vez de se apropriar e de retirar, tem como função maior 'adestrar', ou, sem dúvida, adestrar para retirar e se apropriar ainda mais e melhor. Porém, esta apropriação é unicamente para o seu próprio domínio.

\section{0 corpo 'em risco'}

Subir uma montanha gelada é sentir um frio em forma de faca, é ser objecto de todo um conjunto de transformações fisiológicas e bioquímicas que vão adaptando o corpo até limites da elasticidade biológica que, quando rompem, deixam o utente desse corpo em muito 'maus lençóis' (7). De facto, é indubitável que o risco e o perigo são inerentes ao alpinismo, sendo mesmo apontado como uma das actividades físicas que maior risco envolve $(33,34)$, uma actividade que coloca, potencialmente, a vida em jogo. $\mathrm{O}$ tipo mais frequente de morte é repentina e chocante - um deslizamento ou uma queda numa crevasse - e o maior 'assassino' em termos de números - um enterro numa avalanche (34). São, por conseguinte, inúmeros os riscos a que o alpinista está sujeito. Efectivamente, o perigo nos projectos deste pratican- 
te advém, justamente, do facto destes acontecerem num mundo não preparado que expõe o alpinista a todos os fenómenos ou acidentes que possam ocorrer ${ }^{(4)}$. Assim sendo, é crucial "saber até que ponto se pode esticar esse elo que se pode romper! É um elo metafórico: até onde posso chegar?”(\#9).

Sem dúvida que serão inúmeras as situações que poderão colocar a integridade física do alpinista em risco, ou seja, em que a sua entidade corpórea facilmente poderá estar em causa. De facto, ainda que "muitas vezes não queira estar consciente disso"(\#13), o risco é considerado como um elemento inerente a esta actividade, subsistindo, por isso, uma concordância generalizada entre os alpinistas de que "quando paro e penso, vejo que realmente o risco existe!”(\#15), porque "a partir do momento em que calço os crampons, sei que vou encontrar risco"(\#1). Não obstante, "eu acho que o risco é que acaba por vir a ser gratificante!”(\#16). $\mathrm{Na}$ realidade, o risco é essencial em inúmeras actividades de lazer, constituindo -se, frequentemente, como parte integrante do prazer inerente à sua práti$\mathrm{ca}^{(9)}$. Assim sendo, é de aceitar que alguns dos alpinistas o considerem como "fundamental, porque se o risco não existe, há que o procurar. Não é bem procurar, mas sinto que é aí que está o êxtase completo!"(\#5). É neste conte xto de risco latente que De Léséleuc (8) afirma que praticar alpinismo é como um jogo com a própria vida. Como bem expressa um alpinista, “...é uma metáfora ou um jogo! Mas um jogo em que podes ganhar ou perder! No alpinismo perder pode-se escrever com maiúsculas!"(\#12). Na realidade, no entender de Le Breton (23), este contacto metafórico pode ter poder suficiente para impulsionar longamente uma troca simbólica que favorece uma relação no mundo carregado de sentido, onde o gosto de viver se reconquista. É quando se toma em conta a ausência de referências (superiores ou transcendentes) para a vida na sociedade contemporânea, também secularizada, que se pode admitir a análise de Le Breton. Para este autor, parece notar-se uma falha na nossa sociedade nesta função antropológica de orientação da existência, restando, por isso, a interrogação sobre o significado último: a morte. Neste sentido, quando a ordem social se furta ao seu papel, é necessário experimentar o risco no corpo, uma capacidade íntima de confronto com a morte, sem fraquejar.
Solicitando simbolicamente a morte, confere-se legitimidade à existência, à vida.

$\mathrm{Na}$ realidade, a morte pode ser o preço a pagar pela eventual metamorfose simbólica. Tomando em consideração os factores que propiciam risco a esta actividade, é inevitável que a sua prática implique, eventualmente, não só a possibilidade de insucesso na investida, mas também o sério risco de vida. De facto, a maioria das narrativas dos alpinistas entrevistados aponta para a clara noção de que o 'contacto com a morte' pode realmente acontecer. Mais do que isso, grande parte dos entrevistados viveu situações repletas de risco durante a sua prática, sentindo -se muito próximo da morte. Como relata um dos alpinistas, "tivemos um acidente... Era uma expedição internacional, éramos 3 catalãos e 2 suíços, os suíços morreram!"(\#11). Adicionalmente, alguns alpinistas sofreram acidentes dos quais resultaram marcas indeléveis no corpo, como sejam congelamentos nas mãos, pés e nariz, pois, por exemplo, "no Evereste, naquele risco real, cometi demasiados erros, uma descida tão tardia, o permanecer tanto tempo lá em cima..."(\#3).

Assim sendo, fica guardado um traço indelével sobre o seu corpo ou sobre a sua memória, ficando impregnada em si a prova da investida perigosa, isto é, uma marca tangível sobre a pele, o melhor cartão de identidade para o homem que procura sempre os limites (23). Neste contexto, seria de esperar que este tipo de episódios alterasse, ou pelo menos influenciasse, as expedições futuras ${ }^{(28)}$. Contudo, mesmo sabendo da sua maior susceptibilidade, estes alpinistas continuam a sua actividade, reiterando que "Sim! Sim! Mesmo sabendo que agora é pior! A experiência da montanha é tão compensadora que penso que mais vale perder a vida na montanha do que em acidentes de carro!"(\#11). É como se os alpinistas não se lembrassem das dificuldades por que passaram, pois, apesar de enfatizarem as condições algo adversas à sua actividade, conferem mais importância às boas experiências. No entanto, quando se interroga se vale ou não a pena, a resposta é inequívoca: "O arriscar ao ponto de ir parar a uma cama do hospital, não, não vale a pena! Só que quando arriscamos, não é com essa intenção. Ninguém pensa nessa coisa"(\#3).

Não vale a pena a consequência, porém, é provável que, mesmo que fosse possível voltar atrás, a decisão dos alpinistas fosse semelhante. Efectivamente, 
Young et al(42) demonstraram que em muitos atletas existe uma aceitação paradoxal dos danos corporais provenientes da sua prática desportiva, como se fossem constitutivos da actividade e, por esse motivo, não se configuram como um factor inibidor para regressar à prática. De facto, mesmo conscientes de que algo com consequências graves possa acontecer, “...arriscava! Não consigo explicar porquê... Nós temos aquele objectivo e é a paixão pela montanha que nos faz esquecer um pouco os riscos”(\#17). Assim sendo, parece que os alpinistas continuam a sua prática porque $o$ fascínio que as montanhas exercem e o sentimento de exultação que experimentam ao ascender a uma alta e perigosa montanha suscitam um encanto que os conduz a colocar a sua vida em risco ${ }^{(3)}$.

Neste conte xto, na ausência de limites de sentido que a sociedade já não fornece ${ }^{(23)}$ e, provavelmente, pelo desenvolvimento de manifestações de não conformidade social e pela afirmação de uma atitude mais segura e confiante em relação ao mundo ${ }^{(32)}$, o indivíduo procura em si os limites a atingir (23).

Limites que podem mesmo colocar a integridade física em causa, dado que "se tiver que ficar sem dois dedos para ir ao Shisha Pangma: Vamos embora... é tudo o que se passa à volta dos Himalaias que leva a dizer isso: Dois dedos?! Se calhar dois dedos é um preço certo, se vier de lá com os dedos todos, ainda melhor, mas sem dois dedos, 'na boa'!"(\#5). Parece, pois, que encontrar um limite físico é algo que justifica um sacrifício do corpo.

Segundo Le Breton (23), o limite é uma necessidade antropológica, podendo a busca do mesmo significar, em última análise, uma solicitação da morte para garantir a existência.

Assim sendo, a acção do alpinista parece pautar -se por valores que o orientam para a aquisição de uma recompensa não centrada no seu corpo, mas na totalidade do seu ser, mesmo que dessa acção possam eventualmente resultar danos corporais. Para o alpinista, o corpo não parece ser a sede da existência, mas um invólucro da pessoa. O cume alcançado, o sucesso adquirido pelo 'recorde' e pela conquista, são o resultado no qual se focaliza o sentido da sua actividade, sobrepondo -se o prazer do feito ao risco eventual da vida.

\section{CONCLUSÃO}

Através da interpretação dos discursos, podemos considerar que as categorias criadas demonstram alguns dos sentidos expressos e atribuídos ao alpinismo. Assim, com a categoria 'corpo, um locus de experiência', fica patente um sentido da actividade centrado no valor da estética, sendo este valor realçado pela importância conferida à vivência na montanha e pelas sensações obtidas por todos os elementos que constituem a sua paisagem. Pela categoria 'o corpo na realização de si', desvela-se um sentido focalizado na contínua superação de si, a qual permite essa mesma realização. Com a categoria 'o corpo disciplinado', é perceptível que a disciplina associada ao dever se torna imprescindível para a consecução dos objectivos declarados para a prática do alpinismo. Finalmente, pela categoria 'o corpo em risco', percebemos que a integridade física do alpinista pode mesmo ser colocada em causa, pelo sentimento de exultação experimentado na ascensão às mais altas montanhas. Em suma, o corpo, enquanto entidade axiológica, é vivido na/pela sua funcionalidade, podendo ser, eventualmente, menos bem tratado na tentativa de alcançar os objectivos traçados.

\footnotetext{
Notas

a A transcrição das entrevistas efectuadas aos alpinistas de nacionalidade espanhola foi traduzida para língua portuguesa e submetida a um tradutor qualificado.

${ }^{b}$ Em termos biológicos, a aclimatação à altitude é entendida como um processo comple xo de respostas adaptativas que permitem ao ser humano, a médio e a longo prazo, ajustar -se gradualmente às condições de hipóxia, melhorar a sua performance física e aumentar as possibilidades de sobrevivência nestes ambientes hostis $(9,17)$.

${ }^{c}$ As falas dos alpinistas estão numeradas de acordo com a ordem da realização das entrevistas e transcritas em itálico. Assim, o entrevistado número 1 é identificado como \#1 e assim sucessivamente.
}

\section{CORRESPONDÊNCIA}

Ana Luísa Pereira

Faculdade de Desporto

Universidade do Porto

Rua Dr. Plácido Costa, 91

4200-450 Porto

Portugal

analp@fcdef.up.pt 


\section{REFERÊNCIAS}

1. Bardin L (1977). Análise de conteúdo. Lisboa: Edições 70

2. Baudrillard J (1991). Simulacros e simulação. Lisboa: Relógio d'Água

3. Berbaum E (1998). Sacred Mountains of the world. Los Angeles: University of California Press

4. Bouet M (1968). Signification du sport. Paris: Éditions Universitaires

5. Bourdieu P (1989). O poder simbólico. Lisboa: Difel

6. Bragança de Miranda J (2002). Teoria da Cultura. Lisboa: Edições Século XXI

7. Cunha e Silva P (1997). Anatomias contemporâneas. In Câmara Municipal de Oeiras (ed.). Anatomias contemporâneas. O corpo na arte portuguesa dos anos 90. Oeiras: Câmara Municipal de Oeiras, 49-165

8. De Léséleuc E (1997). Le plaisir du vide. Approche psychanalytique des relations aux vertiges chez les gripeurs et les alpinistes. Corps et Culture 2: 31-44

9. Elias N, Dunning E (1992). A busca da excitação. Lisboa: Difel

10. Foucault M (1995). Vigiar e punir. Rio de Janeiro: Petrópolis

11. Fuster i Matute J, Agurruza B (1995). Riesgo y actividades físicas en el medio natural: un enfoque multidimensional. Apunts (41): 94-107

12. Garcia R (1993). O desporto no universo mítico -religioso: os modelos existenciais revelados pela corrida maratona. Dissertação de Doutoramento. Porto: Faculdade de Ciências do Desporto e de Educação Física, Universidade do Porto

13. Garcia R (1996). Programa e relatório de Antropologia do Desporto. Relatório e programa de disciplina. Provas de Associado. Porto: Faculdade de Ciências do Desporto e de Educação Física, Universidade do Porto

14. Garcia R (1998). Lição de Síntese. Elaborada para a obtenção do título de Agregado no $6^{\circ}$ grupo de disciplinas da FCDEF.UP. Lição de Síntese. Porto: Faculdade de Ciências do Desporto e de Educação Física, Universidade do Porto

15. Garcia R (1999). Da desportivização à somatização da sociedade. In A. Graça (ed.). Contextos da Pedagogia do Corpo. Lisboa: Livros Horizonte, 115-163

16. Ghiglione R, Matalon B (1993). O inquérito. Teoria e prática. Oeiras: Celta Editora

17. Hessen J (1980). Filosofia dos valores. Coimbra: Arménio Amado, Editor, Sucessor (5 ${ }^{\mathrm{a}}$ ed.)

18. Hochachk a PW (1998). Mechanism and evolution of hypoxia-tolerance in humans. J Exp Biol 201 ( Pt 8) 1243-1254

19. Hultgren H (1997). High Altitude Medicine. California: Hultgren Publications

20. Kincheloe J, McLaren P (2000). Rethinking critical theor $y$ and qualitative research. In Y. Lincoln (ed.). Handbook of qualitative research. California: Sage Publications, Inc, 279-313

21. Laverty S (2003). Hermeneutic phenomenology and phenomenology: a comparison of historical and methodological considerations. International Journal of Qualitative Methods 2 (3): 1-29

22. Le Breton D (1999). L'Adieu au Corps. Paris: Éditions Métailié

23. Le Breton D (2000). Passions du risque. Paris: Éditions Métailié (éd. mise à jour)

24. Le Breton D (2002). La sociologie du corps. Paris: Presses Universitaires de France (5e ed.)
25. Lewis $\mathrm{N}$ (2000). The climbing body, nature and the experience of modernity. Body and Society VI (3-4): 58-80

26. Lipovetsk y G (1994). O crepúsculo do dever. A ética indolor dos novos tempos democráticos. Lisboa: Publicações Dom Quixote

27. Loewenstein G (1999). Because it is there: the challenge of mountaineering. Kyklos 52 (3): 315-344

28. Loewenstein G, Hsee C, Weber E, Welch N (2001). Risk as feelings. Psychological Bulletin 127 (2): 267-286

29. Maffesoli M (2001). O eterno instante. O retorno do trágico nas sociedades pós-modernas. Lisboa: Instituto Piaget

30. McCarthy J (2002). A theor y of place in North American mountaineering. Philosophy \& Geography 5 (2): 179-194

31. Merleau-P onty M (1994). Fenomenologia da percepção. S Paulo: Martins Fontes (2a ed., 2a tiragem, 1996)

32. Moura Ferreira P (2003). Comportamentos de risco dos jovens. In J. Pais (ed.). Condutas de risco, práticas culturais e atitudes perante o corpo. Oeiras: Secretaria de Estado da Juventude e Desportos, Celta Editora, 41-166

33. Natalier K (2001). Motorcyclists' interpretations of risk and hazard. Journal of Sociology 37 (1): 65-80

34. Ortner S (1997). Thick resistance: death and the cultural construction of agency in Himalayan mountaineering. Representations 59: 135-162

35. Patrício M (1993). Lições de Axiologia Educacional. Lisboa: Universidade Aberta

36. Queirós P (2002). O corpo na Educação Física. Leitura axiológica à luz de práticas e discursos. Dissertação de Doutoramento. Porto: Faculdade de Ciências do Desporto e de Educação Física, Universidade do Porto

37. Resweber J-P (2002). A Filosofia dos Valores. Coimbra: Almedina

38. Rocchetta C (1993). Hacia una teología de la corporeidad. Madrid: Ediciones Paulinas

39. Stebbins R (1982). Serious leisure: a conceptual statement. Pacific Sociological Review 25: 251-272

40. Vala J (1986). A análise de conteúdo. In J. Madureira Pinto (ed.) Metodologia das Ciências Sociais. Porto: Edições Afrontamento, 101-128

41. Williams T, Donnelly P (1985). Subcultural production, reproduction and transforming climbing. Int. Rev. for Soc. of Sport 20 (1-2): 3-17

42. Young K, Mcteer W, White P (1994). Body talk: male athletes reflect on sport, injury, and pain. Sociology of Sport Journal 11: 175-194 